\title{
Can arginine and ornithine support gut functions?
}

\author{
L Cynober
}

Laboratoire de

Biochimie, Groupe de

Recherche en

Nutrition

Expérimentale et

Metabolisme

Hepatique; Hôpital

Saint - Antoine, Paris,

France, and Centre de

Recherche en

Nutrition Humaine,

Clermont-Ferrand,

France

L Cynober

Correspondence to: Professor L Cynober, Laboratoire de Biochimie, Faculté de Pharmacie, 28 Place H Dunant, BP38, 63001 Clermont-Ferrand Cedex, France.

\begin{abstract}
Arginine and ornithine are precursors of nitric oxide and polyamines, respectively. These metabolites intimately participate in permeability and adaptive responses of the gut. The liver possesses high arginase activity as an intrinsic part of urea synthesis and would consume most of the portal supply of dietary arginine. The gut reduces this possibility by converting dietary arginine to citrulline, which effectively bypass the liver and is resynthesised to arginine in the kidney. Dietary ornithine supplementation, in the form of ornithine $\alpha$-ketoglutarate (OKG) can be considered as an arginine precursor. Several supplement studies have shown both amino acids to promote growth hormone and insulin secretion with anabolic effects in postoperative patients. Their intermediary metabolites (for example, glutamine, proline) may also be of benefit in trauma metabolism. Specific effects of either amino acid on the gut are poorly reported. One recent animal study showed improved morphology after OKG administration, perhaps through increased polyamine secretion. Generation of nitric oxide from arginine has two facets. Excess production from high dose arginine potentiated the effects of experimentally induced sepsis, whereas low doses improved survival. These considerations suggest that the role of enteral diet supplementation with arginine or OKG should be urgently examined for any benefits it may have on mucosal barrier function.
\end{abstract}

(Gut 1994; supplement 1: S42-S45)

For many years, arginine and related compounds (ornithine and citrulline) have been considered solely as intermediate metabolites in the process of nitrogen detoxification - that is, in the context of ureagenesis. There is renewed interest, however, in these amino acids because ureagenesis may have an important role in $\mathrm{pH}$ homeostasis ${ }^{1}$ and also because arginine becomes an essential amino acid during growth and catabolic states. ${ }^{2}$ Ornithine is not a constituent of proteins, but is clearly important in the regulation of nutritional state as a precursor of aliphatic polyamines. In addition, in the form of the $\alpha$ ketoglutarate salt, ornithine generates multiple metabolic effects, which do not result solely to the additive action of the two moieties of this molecule. ${ }^{3}$ There is, however, a paucity of data on the role of arginine or its metabolites in the maintenance of gut function and morphology; this indicates possible future research directions.

\section{Metabolism of arginine and related \\ compounds in the gut}

Arginine synthesis and catabolism in specific tissues is conditioned by the presence of arginosuccinase and arginase respectively, but only periportal hepatocytes and, to some extent, certain brain areas, possess all the enzymes required for arginine recycling and urea synthesis. ${ }^{1}$ The gut acts as a user of arginine because it possesses arginase (isoenzyme II) and ornithine carbamoyltransferase. ${ }^{4}$ The gut thus releases urea and citrulline. ${ }^{5}$ In addition, enterocytes express ornithine decarboxylase ${ }^{6}$ and an $\mathrm{NADPH}_{2}$ dependent arginine deiminase ${ }^{78}$ which respectively lead to local production of aliphatic polyamines and nitric oxide.

Despite the high ornithine decarboxylase activity in enterocytes, however, most of the ornithine produced from arginine is released into the portal blood stream, and polyamine formation accounts for a small part of arginine consumption. ${ }^{8}$

After ${ }^{14} \mathrm{C}$-ornithine is given by the enteral route, ${ }^{14} \mathrm{C}$-proline, ${ }^{14} \mathrm{C}$-glutamate, and ${ }^{14} \mathrm{C}$ polyamines are detected, ${ }^{9}$ as expected, but, in contrast with arginine administration, no citrulline is produced. This could suggest a degree of metabolic compartmentalisation, arginine flux being directed preferentially towards ornithine and citrulline production. Indeed, ornithine translocase, ornithine carbamoyltransferase, and citrulline translocase function as a multienzyme complex ${ }^{1}$ (Fig 1). Figure 2 summarises arginine and ornithine pathways in the gut.

\section{Arginine and related compounds in} artificial nutrition

Arginine has multiple biological properties, including the ability to stimulate anabolic hormone secretion: intravenous and enteral arginine administration increases both insulin and human growth hormone secretion. ${ }^{12}$ Several studies (reviewed in references 2 and 13) show that arginine given to patients as well as in various experimental stress models, acts by improving nitrogen balance, accelerating wound healing, and restoring depressed immunity (Table). These effects are seen whether arginine is given orally ${ }^{14} 15$ or parenterally. ${ }^{16}$

Ornithine shares with arginine the ability to stimulate human growth hormone secretion. ${ }^{3}$ In addition, ornithine as its $\alpha$-ketoglutarate salt (OKG) generates various molecules (for example, glutamine $)^{17}$ which play a key part in the control of protein metabolism. ${ }^{18} \mathrm{OKG}$ has been shown to improve nitrogen balance in various acute and chronic malnutrition states (see reference 3 for a review). OKG increases 


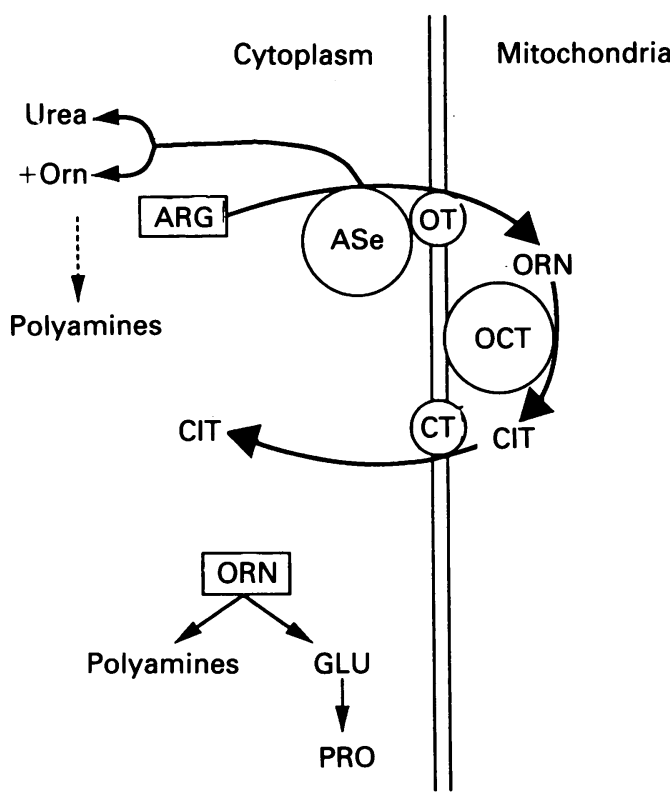

Figure 1: Arginine (ARG) and ornithine (ORN) fluxes compared. $A S e=$ arginase; $O T=$ ormithine translocase; $C T=$ citrulline translocase; $O C T=$ ornithine carbamoyltransferase; $G L U=$ glutamate; $P R O=$ proline.

muscle protein anabolism in moderate catabolic states ${ }^{19}$ and reduces protein catabolism in hypercatabolic states. ${ }^{20}$

\section{Arginine and ornithine in the support of gut functions}

FUNCTIONS OF ARGININE AND ORNITHINE Arginine from dietary proteins is thus actively metabolised in the enterocyte and supports several gut functions. Firstly, arginine metabolism in the enterocyte serves to remove excess arginine, although the liver also has a high capacity for arginine transport and metabolism. ${ }^{21}$ It has been shown ${ }^{22}$ that portal arginine concentrations rise with the percentage of protein in the diet, with a parallel increase in urea synthesis. In fact, arginine acts in the hepatocyte as a positive modulator of $\mathrm{N}$-acetylglutamate synthesis, which is the allosteric obligatory activator of carbamoyl phosphate synthetase, the enzyme participating in the first step of urea synthesis. ${ }^{1}$ Thus, arginine metabolism in the gut should be seen as a means of limiting arginine supply to the liver, thereby limiting ureagenesis when protein intake is low. It is noteworthy that the intestine also contains significant concentrations of $\mathrm{N}$-acetylglutamate ( $20 \%$ of liver content), ${ }^{23}$ which must play a part in favouring citrulline formation from ornithine after food intake. Interestingly, citrulline uptake by the liver is low, and citrulline is extensively converted into arginine in the kidney (Figure 3). Thus, arginine metabolism into

Effects of arginine supplementation in enteral nutrition

$-\downarrow$ protein catabolism in trauma (humans/rats)

- immune response after trauma (humans/rats) thymic weight
thyme response

thymic weight
thymic lymphocyte content

tymphocyte mitotic response to concanavalin $\mathrm{A}$ and PHA

Improves wound healing (humans/rats)

Increases survival after burns (guinea pigs)

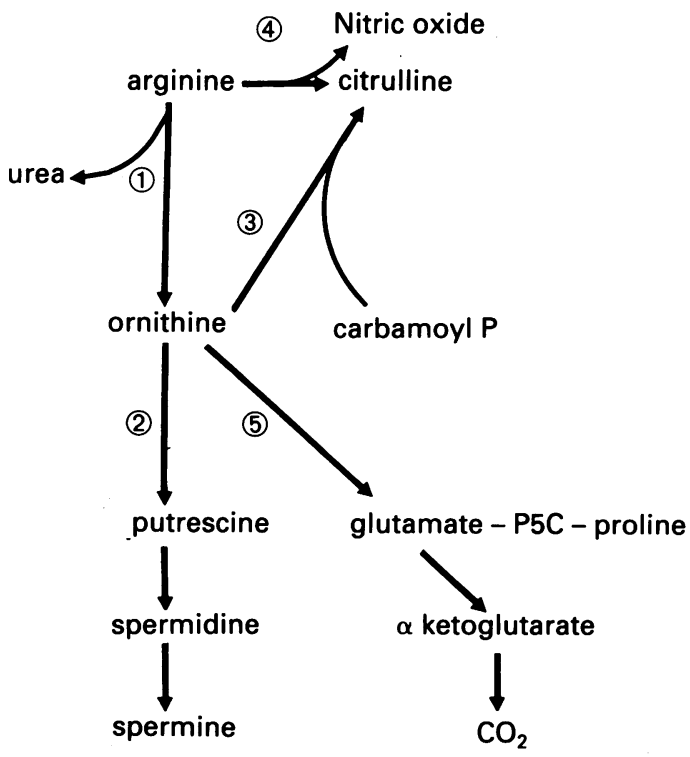

Figure 2: Arginine and ornithine metabolic pathways in the enterocyte. Adapted from Blachier et al. ${ }^{8}$, Seiler et al, 10 and fones. 11 (1) Arginase (EC 3.5.3.1); (2) ornithine decarboxylase (EC 4.1.1.17); (3) ornithine

carbamoyltransferase (EC 2.1.3.3); (4) arginine deiminase; (5) ornithine aminotransferase (EC 2.6.1.13).

citrulline in the gut can also be seen as a means of protecting this amino acid from excessive degradation in the liver. Finally, arginine and ornithine metabolism in enterocytes could participate in the support of gut morphology and function by the synthesis of polyamines and nitric oxide, as will be discussed.

\section{ACTIONS OF ARGININE AND ORNITHINE}

Surprisingly, published works contain few studies dealing with the effects of arginine on gut function and morphology. With regard to ornithine, only one recent study is available (F Raul, personal communication). Rats were starved for three days and then fed for four days by continuous enteral nutrition, with or without supplementation with ornithine $(0.32$ $\mathrm{g} / \mathrm{kg} /$ day) as the $\alpha$-ketoglutarate salt. Rats were then killed and intestinal morphology and enzyme content were studied. Ornithine led to a significantly higher crypt height in the jejunum and ileum and a higher total villous height in the ileum. In addition, sucrase and lactase contents were higher in the ileum of ornithine supplemented rats.

POSSIBLE MECHANISMS OF ACTION (IF ANY)

As described, enterocytes are well equipped to convert arginine into ornithine and to metabolise ornithine into putrescine and other aliphatic polyamines. Alternatively, arginine is the precursor of nitric oxide by arginine desiminase.

\section{The polyamine pathway}

Ornithine is converted into putrescine by ornithine decarboxylase (EC 4.1.1.17), which is the rate limiting enzyme in polyamine synthesis. Putrescine is converted into spermidine by the action of an aminopropyltransferase. A second, identical enzyme adds 


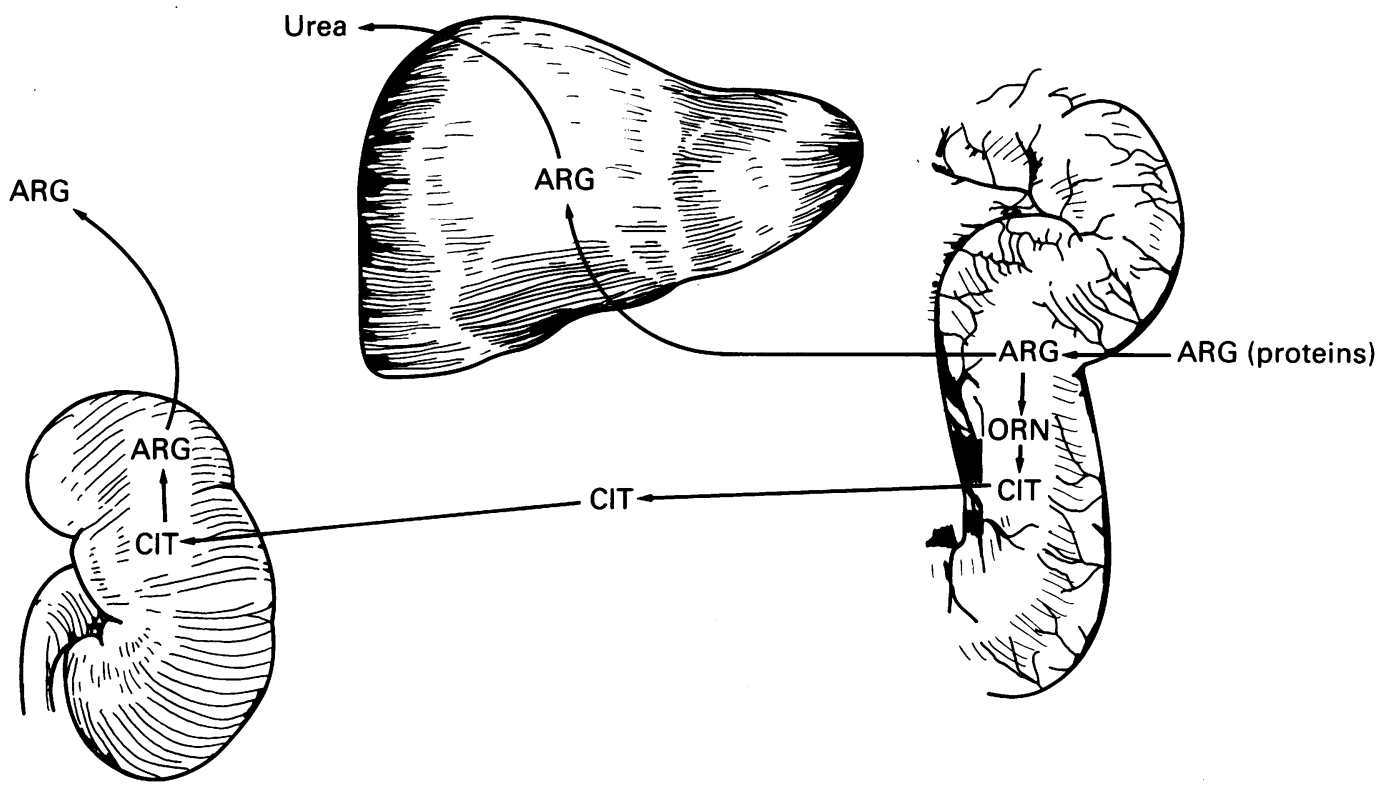

Figure 3: Arginine (ARG) metabolism into citrulline (CIT) in the gut seen as a means of protecting arginine from excessive degradation in the liver. $O R N=$ ornithine.

an additional propylamine moiety to spermidine, thus forming spermidine. The source of the propylamine groups is S-adenosyl methionine. ${ }^{6}$

The functions of polyamines in mammalian cells are poorly understood, although the use of ornithine decarboxylase inhibitors such as difluoromethyl ornithine has established that polyamines are essential for cell growth 6 and protein synthesis. ${ }^{24}$ In this way, it has been clearly shown that the action of ornithine on fibroblast growth in culture ${ }^{25}$ and on protein synthesis by the liver ${ }^{26}$ are both dependent upon polyamine synthesis.

With regard to the intestine, there are consistent data supporting an important role of polyamines in the control of hypo and hyperplasia of this tissue. Ornithine decarboxylase in the mucosa of the small intestine has high basal activity compared with most tissues. ${ }^{6}$ Ornithine decarboxylase is associated with mature cells of the villus tip as well as proliferating crypt cells, suggesting that polyamines participate in both intestinal cell differentiation and proliferation. ${ }^{27}$

Intestinal polyamine content falls after a fast $^{28}$ and after an eight-day total parenteral nutrition programme in the rat, ${ }^{29}$ but increases during refeeding. ${ }^{28}$ The fall in the concentrations of polyamines during fasting results from a simultaneous decrease in polyamine synthesis (that is, a decrease in ornithine decarboxylase content) and an increase in their degradation (that is, an increase in diamine oxydase content). The reverse is true during refeeding. ${ }^{30}$ The trophic effect of nutrients seems to be due in particular to glucose and to amino acids such as glycine and alanine. ${ }^{31} 32$ This effect is strong in the jejunum and ileum, moderate in the duodenum, and small in the proximal colon. ${ }^{31}$

In the same way, during intestinal adaptation in response to jejunectomy $y^{33}$ or to parasite (Trichinella spiralis) induced inflammation, ${ }^{34}$ intestinal contents of ornithine decarboxylase and polyamines increase ${ }^{34}$ in parallel with the increase in mucosal proliferation indices. ${ }^{33}$ This is clear in the distal segment of the intestine where polyamine content is lowest in the basal state. ${ }^{35}$ With the administration of difluoromethylornithine the increase in ornithine decarboxylase and polyamines is suppressed and intestinal adaptation is abrogated. ${ }^{33}$

The real question is whether exogenous arginine can be a relevant precursor of polyamines. It is noteworthy that food contains polyamines and that polyamines are produced by the flora of the gastrointestinal tract. ${ }^{36}$ Thus, the direct uptake by enterocytes of preformed polyamines could contribute to the polyamine cellular pool. Indeed, putrescine ${ }^{37}$ and spermidine uptake ${ }^{38}$ have been shown in isolated rat enterocytes. Interestingly, enterocytes from the distal quarter of the gut exhibit the highest rate of uptake. ${ }^{37}$ The fact that a large fraction of metabolised arginine is transported out of the enterocyte as ornithine and citrulline may show that arginine metabolism is not responsible for relevant amounts of polyamines.

\section{The nitric oxide pathway}

The nitric oxide pathway is probably the most important recent discovery in the field of amino acid metabolism. Nitric oxide is produced from arginine by arginine deiminase. Although this enzyme has been identified in various cell types, the pathway seems to be located mainly in macrophages and endothelial cells, ${ }^{39}$ where nitric oxide triggers cytotoxic activity of phagocytic cells and vascular smooth muscle relaxation of endothelial cells. ${ }^{40}$ Nitric oxide activates guanylate cyclase, thereby forming cyclic GMP, which is its second messenger. ${ }^{39} 40$ Experimental endotoxemia (lipopolysaccharide from Escherichia coll) leads to accumulation of $\mathrm{NO}_{3}{ }^{-}$in urine. Activation of the nitric oxide pathway is controlled by cytokines. ${ }^{41}$ Taken together, the data 
support a role for nitric oxide in the pathogenesis of septic shock syndrome. In this context, care must be taken with arginine supplementation in severely ill patients at risk of developing multiple organ failure. This dual effect of nitric oxide (and therefore arginine) is illustrated by a recent study from Alexander's group. ${ }^{42}$ Septic guinea pigs supplemented with low doses of arginine recovered better than controls, whereas supplementation with high doses led to catastrophic results.

In conclusion, enterocytes contain high concentrations of polyamines, which play a crucial part in the control of cell multiplication and differentiation, and are able to synthesise nitric oxide, which emerges as a potent modulator of the response to inflammation. Despite these features, there is an extreme paucity of data on the action of arginine and ornithine on gut function. Such studies are urgently required.

I am extremely grateful to Dr F Raul (INSERM U61, Strasbourg) for providing exciting new results on the effects of ornithine $\alpha$-ketoglutarate on gut morphology and function. The secretarial assistance of Miss P Jue was greatly appreciated.

1 Meijer AJ, Lamers WH, Chamuleau RAFM. Nitrogen metabolism and ornithine cycle function. Physiol Rev 1990; 70: 701-48.

2 Barbul A. Arginine: biochemistry, physiology and therapeutic implications. FPEN 1986; 10: 227-38.

3 Cynober L. Ornithine alpha-ketoglutarate in nutritional support. Nutrition 1991; 7: 313-22.

4 Herzfeld A, Raper SM. The heterogeneity of arginases in rat tissues. Biochem $\mathcal{F}$ 1976; 153: 469-78.

5 Windmueller HG, Spaeth AE. Metabolism of absorbed aspartate, asparagine, and arginine by rat small intestine aspartate, asparagine, and arginine by rat small inte
in vivo. Arch Biochem Biophys 1976; 175: 660-76.

6 Pegg AE. Recent advances in the biochemistry of polyamines in eukaryotes. Biochem f 1986; 234: 249-62.

7 Blachier F, M'Rabet-Touil H, Darcy-Vrillon B, Posho L, Duee PH. Stimulation by $\mathrm{D}$-glucose of the direct conversion of arginine to citrulline in enterocytes isolated from pig jejunum. Biochem Biophys Res Commun 1991; 177: 1171-7.

8 Blachier F, Darcy-Vrillon B, Sener A, Duee PH, Malaisse WJ. Arginine metabolism in rat enterocytes. Biochim Biophys Acta 1991; 1092: 304-10.

9 Vaubourdolle M, Jardel A, Coudray-Lucas C, Ekindjian OG, Agneray J, Cynober L. Fate of enterally administered ornithine in healthy animals: interactions with alphaornithine in healthy animals: interaction

10 Seiler N, Daune G, Bolkenius FN, Knodgen B. Ornithine aminotransferase activity, tissue ornithine concentrations and polyamines metabolism. Int $\mathcal{F}$ Biochem 1989; 21: 425-32.

11 Jones ME. Conversion of glutamate to ornithine and proline: pyrroline 5-carboxylate, a possible modulator of arginine requirement. $\mathcal{F}$ Nutr 1985 ; 115: 509-15.

12 Merimee TJ, Lillicrap DA, Rabinowitz D. Effect of arginine on serum-levels of human growth hormone. Lancet 1965; ii: $668-70$.

13 Barbul A. Arginine and immune function. Nutrition 1990; 6: 53-8.

14 Seifter E, Rettura G, Barbul A, Levenson SM. Arginine: an essential amino acid for injured rats. Surgery 1978; 84: 224-30.

15 Barbul A, Lazarou SA, Efron BA, Wasserkrug HL, Efron G. Arginine enhances wound healing and lymphocyte immune responses in humans. Surgery 1990; 108: 331-7.

16 Leon P, Redmond P, Stein TP, Shou J, Schulter MD, Kelly $\mathrm{C}$, et al. Arginine supplementation improves histone and acute-phase protein synthesis during gram-negative sepsis in the rat. $\mathscr{F} P E N$ 1991; 15: 503-8.

17 Cynober L, Coudray-Lucas C, De Bandt JP, Guechot J, Aussel C, Salvucci M, et al. Action of ornithine alphaketoglutarate, ornithine hydrochloride and calcium alphaketoglutarate on plasma amino acid and hormonal patterns in healthy subjects. $\mathcal{f}$ Am Coll Nutr 1990; 9: 2-12.
18 Rennie MJ, Babij P, Taylor PM, Hundal HS, Mac Lenan P, Watt PW, et al. Characteristics of a glutamine carrier in skeletal muscle have important consequences for nitrogen loss in injury, infection and chronic disease. Lancet 1986; ii: $1008-12$.

19 Wernerman J, Hammarqvist F, Ali MR, Vinnars E. Glutamine and ornithine alpha-ketoglutarate but not branched-chain amino acids reduce the loss of muscle glutamine after surgical trauma. Metabolism 1989; 38 (suppl 1): 63-6.

20 Vaubourdolle $M$, Coudray-Lucas C, Jardel A, Ziegler F, Ekindjian OG, Cynober L. Action of enterally-administered ornithine alpha-ketoglutarate on protein breakdown in skeletal muscle and liver of the burned rat. $\mathcal{F P E N ~ 1 9 9 1 ; ~}$ 15: 517-20.

21 De Bandt JP, Cynober L, Lim SK, Coudray-Lucas C, Poupon R, Giboudeau J. Métabolismes comparés de l'ornithine et de l'arginine dans un systéme de foie isolé perfusé. Nutr Clin Métabol 1990; 4 (suppl): 46.

22 Morimoto BH, Brady JF, Atkinson DE. Effect of level of dietary protein on arginine-stimulated citrulline synthesis. Biochem f 1990; 272: 671-5.

23 Tuchman M, Holznecht RA. N-acetylglutamate content in liver and gut of normal and fasted mice, normal human livers, and livers of individuals with carbamyl phosphate synthetase or ornithine transcarbamylase. Pediatr Res 1990; 27: 408-12.

24 Grillo MA. Metabolism and function of polyamines. Int $\mathcal{F}$ Biochem 1985; 17: 943-8.

25 Vaubourdolle M, Salvucci M, Coudray-Lucas C, Agneray J, Cynober L, Ekindjian OG. Action of ornithine alphaketoglutarate on DNA synthesis by human fibroblasts. In Vitro Cell Dev Biol 1990; 26: 187-92.

26 Oratz M, Rothschild MA, Schreiber SS, Burks A, Mongelli J, Matarese B. The role of the urea cycle and polyamines in albumine synthesis. Hepatology 1983; 3: 567-630.

27 Johnson LR, Tseng CC, Wang P, Tipnis UR, Haddox MK. Mucosal ornithine decarboxylase in the small intestine: localization and stimulation. Am $\mathcal{f}$ Physiol 1989; 256: G624-30.

28 Alarcon P, Lin CH, Lebenthal E, Lee PC. Interaction of malnutrition and difluoromethylornithine induced intestinal mucosal damage: degree of severity and subsequent recovery. Digestion 1988; 41: 68-77.

29 Hosomi M, Stace NH, Lirussi F, Smith SM, Murphy GM, Dowling RH. Role of polyamines in intestinal adaptation Dowling RH. Role of polyamines in intestinal

30 D'Agostino L, Daniele B, Pignata S, Barone MV, D'Argenio G, Mazzaca G. Modifications in ornithine decarboxylase and diamine oxidase in small bowel mucosa of starved and refed rats. Gut 1987; 28 (suppl 1): 135-8.

31 Jain R, Eikenburg BE, Johnson LR. Stimulation of ornithine decarboxylase activity in digestive tract mucosa. $A m \mathcal{F}$ Physiol 1987; 253: G303-7.

32 Minami H, Mikamoto K, Fujii Y, Nakabou Y, Hagihira H. Induction of intestinal ornithine decarboxylase by single amino acid feeding. F Biochem 1985; 98: 133-9.

33 Luk GD, Yang P. Polyamines intestinal and pancreatic adaptation. Gut 1987; 28 (suppl 1): 95-101.

34 Wang JY, Johnson LR, Tsai YH, Castro GA. Mucosal ornithine decarboxylase, polyamines, and hyperplasia in ornithine decarboxylase, polyamines, and hyperpla

35 Hosomi MM, Smith SM, Murphy GM, Dowling RH. Polyamine distribution in the rat intestinal mucosa. 7 Chromatogr 1986; 375: 267-75.

36 McCormack SA, Johnson LR. Role of polyamines in gastrointestinal mucosal growth. Am $\mathcal{f}$ Physiol 1991; 260: G795-806.

37 Kumagai J, Johnson LR. Characteristics of putrescine uptake in isolated rat enterocytes. Am $\mathcal{F}$ Physiol 1988; 254: G81-6.

38 Kumagai J, Jain R, Johnson LR. Characteristics of spermidine uptake by isolated rat enterocytes. Am f Physiol 1989; 256: G905-10

39 Marletta MA. Nitric oxide: biosynthesis and biological significance. Trends in Biological Sciences 1989; 14: 488-92.

40 Moncada S, Palmer RMJ, Higgs EA. Biosynthesis of nitric oxide from L-arginine. A pathway for the regulation of cell function and communication. Biochem Pharmacol 1989; 38: $1709-15$.

41 Kilbourn RG, Gross SS, Jubran A, Adams J, Griffith OW, Levi R, et al. N-methyl-L-arginine inhibits tumor necrosis factor-induced hypotension: implications for the involvement of nitric oxide. Proc Natl Acad Sci USA 1990; 87: 3629-32.

42 Gonce SJ, Peck MD, Alexander JW, Miskell PW. Arginine supplementation and its effect on established peritonitis in guinea pigs. FPEN 1990; 14: 237-44. 